ORIGINAL ARTICLE

\title{
Agreement between community echocardiography and hospital echocardiography in patients suspected of having left ventricular systolic dysfunction
}

\author{
S Jeyaseelan, B M Goudie, S D Pringle, P T Donnan, F M Sullivan, A D Struthers
}

Postgrad Med J 2005;81:777-779. doi: 10.1136/pgmj.2005.033605

See end of article for authors' affiliations

....................

Correspondence to: Dr S Jeyaseelan,

Department of Cardiology, Freeman Hospital,

Freeman Road, Newcastle upon Tyne NE7 7DN, UK; sjeyaseelan@doctors.org.

Submitted

20 February 2005

Accepted 6 April 2005
Background: Smaller echocardiography machines, when used in hospitals, are accurate for detecting left ventricular dysfunction and valvular disease. This paper assessed the detection of left ventricular dysfunction and of valvular disease in the community setting by a smaller machine.

Aims: To measure the agreement in patients with suspected heart failure between community echocardiography and traditional echocardiography in the hospital in detecting left ventricular dysfunction and significant valve disease.

Methods: Suspected heart failure patients were referred to one of the authors (SJ) for community echocardiography using a Siemens Cypress machine. The patients had a second echocardiogram in the hospital by another sonographer who was blinded to the results of the first echocardiogram. The reports of the two sonographers were assessed for agreement using $\mathrm{k}$ statistics.

Results: 458 patients had a community echocardiogram and 136 agreed to a second echocardiogram in the hospital. There was excellent agreement, $\kappa=0.87(0.06 \mathrm{SE})$, for the detection of left ventricular dysfunction between community echocardiography and the hospital machine. The detection of significant valvular disease was good, $\kappa=0.75(0.06)$ between the community echocardiogram and hospital machines.

Conclusions: In suspected heart failure patients, community echocardiography gives comparable results to traditional hospital echocardiography for left ventricular dysfunction detection and for significant valvular disease detection.
$P$ atients with breathlessness and ankle oedema presenting to their general practitioner may have heart failure. Echocardiography is the key investigation for assessing suspected heart failure patients. ${ }^{12}$ Unfortunately, the availability of echocardiography is suboptimal in the UK. ${ }^{34}$ Advances in ultrasound technology have led to the development of smaller echocardiography machines that may be transported more easily to different sites in the community. Studies have found that smaller echocardiography machines, when used in hospitals by experts, are accurate for detecting left ventricular systolic dysfunction and valvular disease. ${ }^{56}$ However, studies have not looked at the performance of these smaller echocardiogram machines in community settings where conditions may be different such as suitable couches, lighting, and lack of immediate second opinion.

\section{AIMS}

Hospital echocardiography, when performed by a BSE accredited sonographer, is the standard form of assessment for most suspected heart failure patients. We wished to measure the agreement, by $\kappa$ statistics, for the detection of left ventricular systolic dysfunction in suspected heart failure patients between community echocardiography using a smaller machine and traditional echocardiography in the hospital. We also wished to measure the agreement for the detection of significant valvular disease between community echocardiography and hospital echocardiography. If there is good agreement between community echocardiography and traditional echocardiography, when performed by hospital practitioners, then there is a role for community echocardiography in the diagnosis of left ventricular systolic dysfunction. Furthermore, there is the possibility of community echocardiography being performed by appropriately trained community based health care practitioners. However, if the agreement is poor between community echocardiography and hospital echocardiography when performed by hospital practitioners then community echocardiography should not be done. Resources should then be directed to either improving access to hospital echocardiography or using screening tests such as brain natriuretic peptides. $^{37}$

\section{METHODS}

\section{Patients and settings}

The study was conducted in the Dundee, Angus, and North East Fife region of Scotland between June 2002 and September 2003. Patients who were suspected of having heart failure by their general practitioners and not been diagnosed with an echocardiogram before were referred for an echocardiogram in the community. All the patients complained of breathlessness, tiredness, or ankle swelling. The patients had their echocardiogram in one of seven community centres, which included five GP surgeries, an out of hours GP centre, and two community hospitals. Patients were then invited to attend for a second echocardiogram at Ninewells Hospital using a standard machine, a Hewlett Packard Sonos 2500, to check the accuracy of the portable machine in the community. The investigation conforms to the principles outlined in the Declaration of Helsinki. Patients all gave written informed consent to participate in this study. The Tayside research ethics committee and the North East Fife ethics committee approved the ethics of this study. 
Table 1 Agreement for echocardiogram reporting by the two sonographers analysing the same 10 echocardiograms

\begin{tabular}{lll}
\hline $\begin{array}{l}\text { Echocardiography } \\
\text { assessment }\end{array}$ & $\kappa$ Value (SE) & $\begin{array}{l}\text { Weighted } \kappa \text { value } \\
\text { (SE) }\end{array}$ \\
\hline $\begin{array}{l}\text { Left ventricular systolic } \\
\text { function classification* }\end{array}$ & $1.00(0.00)$ & $1.00(0.00)$ \\
$\begin{array}{l}\text { Mitral valve stenosis } \\
\text { Mitral valve regurgitation }\end{array}$ & $1.00(0.00)$ & $1.00(0.00)$ \\
$\begin{array}{l}\text { Tricuspid valve } \\
\text { regurgitation }\end{array}$ & $0.69(0.19)$ & $0.82(0.17)$ \\
Aortic valve stenosis & $1.00(0.00)$ & $0.74(0.17)$ \\
Aortic valve regurgitation & $0.83(0.17)$ & $1.00(0.00)$ \\
\hline
\end{tabular}

*Left ventricle systolic function classed as either normal or mildly, moderately, severely impaired.

\section{Sonographers}

S Jeyaseelan, a cardiology registrar, performed the portable echocardiograms in the community with a Siemens Cypress System without access to any prior investigations. C McLeod, a senior cardiac technician, performed the second echocardiograms using a Hewlett Packard Sonos 2500 machine without any knowledge of the first echocardiogram. We first assessed interobserver reporting variability between $\mathrm{S}$ Jeyaseelan and C McLeod using 10 random echocardiograms from patients who had not participated in the study and that had been performed by a third party. S Jeyaseelan and C McLeod reported these 10 echocardiograms independently without access to previous reports of them. The reporting agreement between the two sonographers was found to be good for key features (table 1). Strength of agreement was assessed using $\kappa$ statistics with SPSS version 11.0. Using Landis and Koch criteria, a $\kappa$ value greater than 0.75 represents excellent agreement, those between 0.4 and 0.75 are fair to good agreement, and those less than 0.4 are poor agreement. Weighted $\kappa$ statistics were calculated for echocardiographic abnormalities, which could be graded as to whether they were mild, moderate, or severe. Weighted $\kappa$ statistics are a way of assessing the degree of disagreement between observers, for example, if one observer classifies an abnormality as normal where the other classifies it as severely abnormal then the $\kappa$ statistic would decrease considerably whereas it would decrease much less if the degree of disagreement was small.

\section{Echocardiography}

Left ventricular dysfunction was defined as an ejection fraction less than 50\% using Simpson's method of discs in the apical 4 and 2 chamber views, or a fractional shortening of less than $25 \%$, or if neither of these assessments were
Table 3 Agreement between the community echocardiogram report and the hospital echocardiogram report for the same 136 patients

\begin{tabular}{|c|c|c|}
\hline $\begin{array}{l}\text { Echocardiography } \\
\text { assessment }\end{array}$ & $\kappa$ Value (SE) & $\begin{array}{l}\text { Weighted } \kappa \text { value } \\
\text { (SE) }\end{array}$ \\
\hline $\begin{array}{l}\text { Left ventricular systolic } \\
\text { dysfunction detection* }\end{array}$ & $0.87(0.06)$ & N/A \\
\hline Mitral valve stenosis & $1.00(0.00)$ & $1.00(0.00)$ \\
\hline Significant mitral stenosis & $1.00(0.000)$ & N/A \\
\hline Mitral valve regurgitation & $0.39(0.07)$ & $0.40(0.06)$ \\
\hline Significant mitral regurgitation & $0.51(0.10)$ & N/A \\
\hline Aortic valve stenosis & $0.55(0.16)$ & $0.65(0.15)$ \\
\hline Significant aortic stenosis & $1.00(0.00)$ & N/A \\
\hline Aortic valve regurgitation & $0.64(0.06)$ & $0.63(0.05)$ \\
\hline Significant aortic regurgitation & $0.60(0.16)$ & N/A \\
\hline Tricuspid valve regurgitation & $0.30(0.69)$ & $0.39(0.06)$ \\
\hline $\begin{array}{l}\text { Significant tricuspid } \\
\text { regurgitation }\end{array}$ & $0.53(0.10)$ & N/A \\
\hline $\begin{array}{l}\text { Significant valve disease of } \\
\text { any kind }\end{array}$ & $0.75(0.06)$ & N/A \\
\hline
\end{tabular}

possible "eye-ball" gauging of function was used. ${ }^{8}$ Valvular function was assessed using 2D, colour 2D, and Doppler studies. Valvular function was classified into normal or mildly or moderately or severely diseased. Significant valve disease was said to be present when at least a moderate abnormality was found. The echocardiogram was reported immediately after the examination was performed.

\section{RESULTS}

During the study period, 458 patients with suspected heart failure were referred for echocardiography in the community. For logistical reasons we were unable to do second echocardiograms in all 458 patients. Therefore, of these 458 patients, 136 patients were asked to attend the hospital for a second echocardiogram. The characterstics of the two groups of patients were not significantly different for age, sex, ankle oedema, and past cardiovascular disease (table 2). However, this group of 136 patients was deliberately enriched with more cases of left ventricular systolic dysfunction as it was the accuracy of detection of this abnormality that was the prime reason for the study. Indeed, nearly $70 \%$ of those with left ventricular systolic dysfunction among the 458 patients had a second echocardiogram. Table 3 shows the various strengths of agreement between the community echocardiogram and the hospital echocardiogram for key features. There was excellent agreement, $\kappa$ statistic $0.87(0.06)$, for the detection of left ventricular systolic dysfunction. Agreement for significant valve disease diagnosis was very good, $\kappa$ statistic 0.75 (0.05). However, for each valve, there was

Table 2 Characteristics of the patients presenting for a portable echocardiogram and for a hospital echocardiogram

\begin{tabular}{|c|c|c|c|c|}
\hline & \multirow{2}{*}{$\begin{array}{l}\text { Portable } \\
\text { echocardiogram } \\
\text { patients ( } n=458 \text { ) }\end{array}$} & \multirow{2}{*}{$\begin{array}{l}\text { Hospital } \\
\text { echocardiogram } \\
\text { patients }(n=136 \text { ) }\end{array}$} & \multirow{2}{*}{$\begin{array}{l}\text { Independent } t \\
\text { test }\end{array}$} & \multirow{2}{*}{$\frac{\text { Pearson } \chi^{2}}{p \text { value }}$} \\
\hline & & & & \\
\hline Mean age (SD) & $72.6(9.7)$ & $71.8(8.3)$ & 0.184 & \\
\hline Male (\%) & $184(40.2)$ & $59(43.4)$ & & 0.363 \\
\hline Breathlessness (\%) & 400 (87.3) & $128(94.1)$ & & 0.005 \\
\hline Oedema $(\%)$ & $302(65.9)$ & $85(62.5)$ & & 0.313 \\
\hline Lethargy $(\%)$ & $254(55.5)$ & $79(58.1)$ & & 0.462 \\
\hline $\begin{array}{l}\text { Ischaemic heart disease } \\
(\%)\end{array}$ & $176(38.4)$ & $54(39.7)$ & & 0.715 \\
\hline Hypertension (\%) & $218(47.6)$ & $65(47.8)$ & & 0.957 \\
\hline $\begin{array}{l}\text { Left ventricular systolic } \\
\text { dysfunction (\%) }\end{array}$ & $37(8.1)$ & $25(18.4)$ & & 0.000 \\
\hline
\end{tabular}


variation in the agreement for severity of disease. Agreement for aortic valve disease was good. Classification for mitral and tricuspid regurgitation was less satisfactory, $\kappa$ statistic 0.40 (0.06) and 0.39 (0.06) respectively. This difference was attributable to identification between no regurgitation and trivial regurgitation and between trivial regurgitation and mild regurgitation.

\section{DISCUSSION}

Our study, which investigated suspected heart failure patients, found that there was excellent agreement between echocardiography in the community using a smaller machine and hospital echocardiography for the detection of left ventricular systolic dysfunction. Furthermore, the agreement between the community echocardiogram and the hospital echocardiogram for any type of significant valve disease was good. Differences between the two ways of investigating patients did seem to exist, but only at the level of milder valvular abnormalities. Some of this will be down to differences in the two sonographers' reporting techniques, as the agreement on reporting on the same echocardiograms was not perfect (table 1). The different backgrounds of the two sonographers, one was medically trained and the other was a technician, would have contributed to this. Left ventricular diastolic dysfunction is another cause of heart failure in this study's age group. ${ }^{9}$ However, there is a lack of consensus for diagnosing diastolic heart failure in the community. ${ }^{10}$ Therefore, our study was aimed at left ventricular systolic dysfunction. Overall, it seems community echocardiography with the Siemens Cypress system does give similar results to a hospital echocardiography for detecting left ventricular systolic dysfunction and for detecting significant valvular disease in suspected heart failure patients. Therefore, the possibility of developing community echocardiography services in the community is feasible.

A cardiology trained research fellow performed the community echocardiography in this study. It seemed sensible to us to first assess how an expert performed in this setting with this new machine. The next step is to assess whether other health care professionals (for example, nurses) could be trained to successfully deliver a service such as this. Studies in the future should now look at whether health care professionals from the community can be trained to provide similar accuracy with community echocardiography.

\section{Authors' affiliations}

S Jeyaseelan, Department of Cardiology, Freeman Hospital, Newcastle upon Tyne, UK

B M Goudie, Westgate Health Centre, Dundee, UK

S D Pringle, Department of Cardiology, Ninewells Hospital, Dundee, UK

P T Donnan, F M Sullivan, Division of Community Health Sciences,

University of Dundee, Dundee, UK

A D Struthers, Division of Medicine and Therapeutics, University of Dundee, Ninewells Hospital

Funding: British Heart Foundation funded project.

Competing interests: none declared.

\section{REFERENCES}

1 Scottish Intercollegiate Guidelines Network. Guidelines for diagnosis and treatment of heart failure due to left ventricular systolic dysfunction. Edinburgh: SIGN, 1999.

2 Francis CM, Caruana L, Kearney $P$, et al. Open access echocardiography in management of heart failure in the community. BMJ 1995;310:634-6.

3 National Institute for Clinical Excellence. Chronic heart failure. National clinical guidelines for diagnosis and management in primary and secondary care. London: NICE, 2003.

4 Khunti K, Hearnshaw $\mathrm{H}$, Baker $\mathrm{R}$, et al. Heart failure in primary care: qualitative study of current management and perceived obstacles to evidencebased diagnosis and management by general practitioners. European Journal of Heart Failure 2002;4:771-7.

5 Galasko GIW, Lahiri A, Senior R. Portable echocardiography: an innovative tool in screening for cardiac abnormalities in the dommunity. European Journal of Echocardiography 2003;4:119-27.

6 Senior R, Galasko G, McMurray JV, Mayet J. Screening for left ventricular dysfunction in the community: role of hand held echocardiography and brain natriuretic peptides. Heart 2003;89:iii24-8.

$7 \mathrm{Ng}$ LL, Loke I, Davies JE, et al. Identification of previously undiagnosed left ventricular systolic dysfunction: community screening using natriuretic peptides and electrocardiography. European Journal of Heart Failure 2003;5:775-82.

8 McGowan JH, Cleland JGF. Reliability of reporting left ventricular systolic function by echocardiography: a systematic review of 3 methods. Am Heart $J$ 2003; 146:388-97.

9 van Kraaii DJW, van Pol PEJ, Ruiters AW, et al. Diagnosing diastolic heart failure. European Journal of Heart Failure 2002;4:419-30.

10 Vasan RS, Levy D. Defining diastolic heart failure. A call for standardized diagnostic criteria. Circulation 2002;101:2118-21. 